\title{
THE EFFECT OF FORESHORE SLOPE ON BREAKWATER STABILITY
}

\author{
Henk Jan Verhagen ${ }^{1}$, Bas Reedijk ${ }^{2}$ and Marcus Muttray ${ }^{2}$
}

\begin{abstract}
Experience has shown that stability parameters for breakwater armour are different for steep and shallow foreshores, as well as for deep and shallow water. A change from a deep water spectral information $\left(T_{m 0}\right)$ to shallow water spectral information $\left(T_{m-1,0}\right)$ does not completely explains this difference. Tests have shown that stability also depends on parameters not described by the spectrum at the toe of the breakwater. It is suggested that these parameters include for example the skewness of the waves.
\end{abstract}

\section{The problem history}

In case of coasts with steep foreshores coastal structures suffer more from damage than normally could be expected from given boundary conditions at deep water. For that reason in many guidelines it is recommended to apply a heavier class of rock in those cases; manufacturers of single layer units (like Accropode, Core-loc or Xbloc) recommend a lower $K_{d}$ value in case of a steep foreshore. Unfortunately until recently there was no insight in the physical processes leading to this extra load. In the stability formula of VAN DER MEER [1988] shallow water and steep foreshores are not considered.

The original formula (for plunging conditions) of Van der Meer reads:

$$
\frac{H_{s}}{\Delta D_{n 50}}=c_{\text {plunging }} \xi^{-0.5} P^{0.18}\left(\frac{S}{\sqrt{N}}\right)^{1 / 5}
$$

The coefficient $c_{\text {plunging }}$ has a value of 5.0

A first step into a more systematic analysis of problem of shallow water and steep foreshores has been the systematic research on the interaction between waves and structures in case of shallow foreshores by VAN GENT ET AL.[2003]. The main result of this research was that the load on the structure can better described by a shallow water spectrum at the toe of the structure. And because the longer periods are more relevant than the shorter periods, more weight should be given to the low frequency part of the spectrum. This can be done by using in stability formula as parameter for the wave energy not the $T_{p}$ or $T_{m 0}$, but

${ }^{1}$ Faculty of Civil Engineering, Delft University of Technology, PO Box 5048, NL2600CN

Delft, Netherlands, H.J.Verhagen@tudelft.nl

${ }^{2}$ Delta Marine Consultants, PO Box 268, NL2800 AG Gouda, Netherlands,

B.Reedijk@dmc.nl; M.Muttray@dmc.nl 
the $T_{m-1,0}$. This parameter gives more reliable results both for run-up/overtopping formula as well as for stability formula.

Van Gent, following a statement of VAN DER MEER [1988, p81] stated that for shallow water conditions instead of the significant wave height it is better to use the $2 \%$ wave height, and to calculate the value of $\xi$ with the spectral wave period $T_{m-1,0}$. This leads to the following equation for plunging waves:

$$
\frac{H_{s}}{\Delta D_{n 50}}=c_{\text {plunging }} \xi_{s,-1}^{-0.5} P^{0.18}\left(\frac{H_{2 \%}}{H_{s}}\right)^{-1}\left(\frac{S}{\sqrt{N}}\right)^{1 / 5}
$$

This formula has been calibrated on the dataset of Van Gent. Calibration of the formula leads to a value of $c_{\text {plunging }}$ of 8.4 . A comparable transformation can be carried out for surging waves.

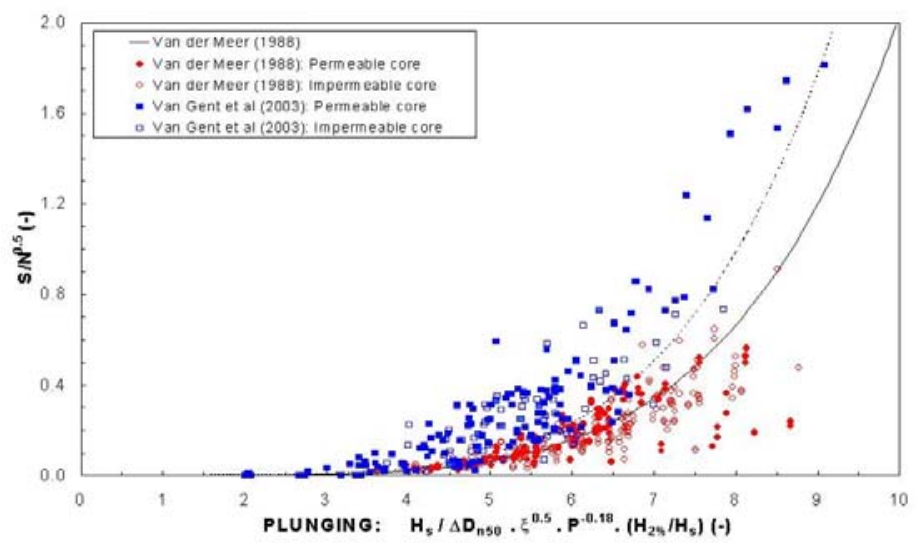

Figure1: Data of VAN GENT [2003] and VAN DER MEER [1988] (from VAN GENT[ 2004])

\section{The present problem}

As can be seen from Figure 1, even after correction of the data as indicated in equation (2), there is a significant difference between the dataset of Van der Meer and the dataset of Van Gent. Thorough investigation of both the test sets of Van der Meer and of Van Gent could not identify systematic differences in the modelling approach. The differences between the tests is that Van der Meer focused of tests with horizontal bed in front of the construction (80\% of his tests) and deep water (the ratio $H_{s} / d$ varied between 0.12 and 0.26 ), while Van Gent focused on slopes (1:100 and 1:30) and shallow water (the ratio $H_{s} / d$ varied from 0.23 to $0.78 \mathrm{~m}$; few test were between 0.15 and 0.23 ). However, these effects are accounted for in the transformation from deep water spectra to shallow water spectra. 


\section{Recent tests on steep slopes}

Because the stability of breakwaters at steep slopes is still a problem, it has been decided to focus some laboratory tests on this problem. A number of tests were done in the research flume of the Laboratory of Fluid Mechanics of Delft

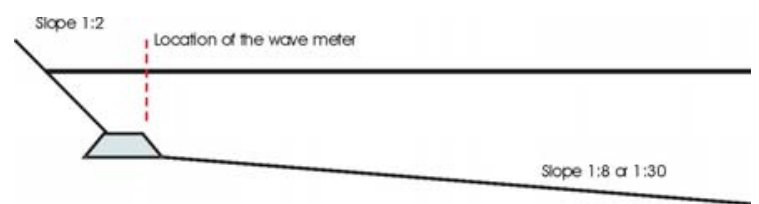

Figure 2: Test set-up in the laboratory
University of Technology. In the flume a 1:2 (permeable) breakwater has been constructed on a 1:8 foreshore and on a 1:30 foreshore. The toe of the breakwater was also made of riprap, but fixed with chicken wire to prevent any damage to the toe. Of course it is questionable if a 1:8 foreshore should be considered as a foreshore or as a part of the structure. However, these two slopes were selected in order to see clearly the differences in slope effects. The wave flume has full reflection compensation. Several series of tests were done, but relevant in this framework are two series.

The basic setting of these series is a wave height at the wave maker $H_{m 0,0}=$ $12.1 \mathrm{~cm}$ and a wave period of $T_{p}=1.6$ seconds. The water depth is $66 \mathrm{~cm}$, the rock had a size of $D_{n 50}$ of $1.57 \mathrm{~cm}$ and a specific density of $\rho=2789 \mathrm{~kg} / \mathrm{m}^{3} \mathrm{In}$ the first series the wave at the wave board was kept identical, in the second series the wave at the toe of the structure was kept identical. In this second series, a wave spectrum was generated in such a way that the incoming spectrum at the toe of the breakwater was exactly the same for both the 1:8 and the 1:30 slope. The damage on the breakwater was investigated for a number of wave conditions. The results are presented in figure 3. As a standard procedure the wave at the toe has been decomposed in an incoming wave and a reflected wave. In the experiment described in figure 3 the (decomposed) incoming waves are made identical.

As expected, for equal deep water waves, the damage in case of a steep slope is more than in case of a gentle slope. However, also in the tests with identical waves at the toe of the breakwater, the steeper slope resulted in significantly more damage than the more gentle slope. Especially with a wave steepness in the order of 1.2 the difference in damage is significant.

Because the spectra are identical, and the damage is clearly not identical, this implies that the damage to the breakwater also has to depend on a wave parameter which is not represented by the shallow water wave energy spectrum, and it has to be a parameter which is different for waves approaching over different foreshore slopes. 

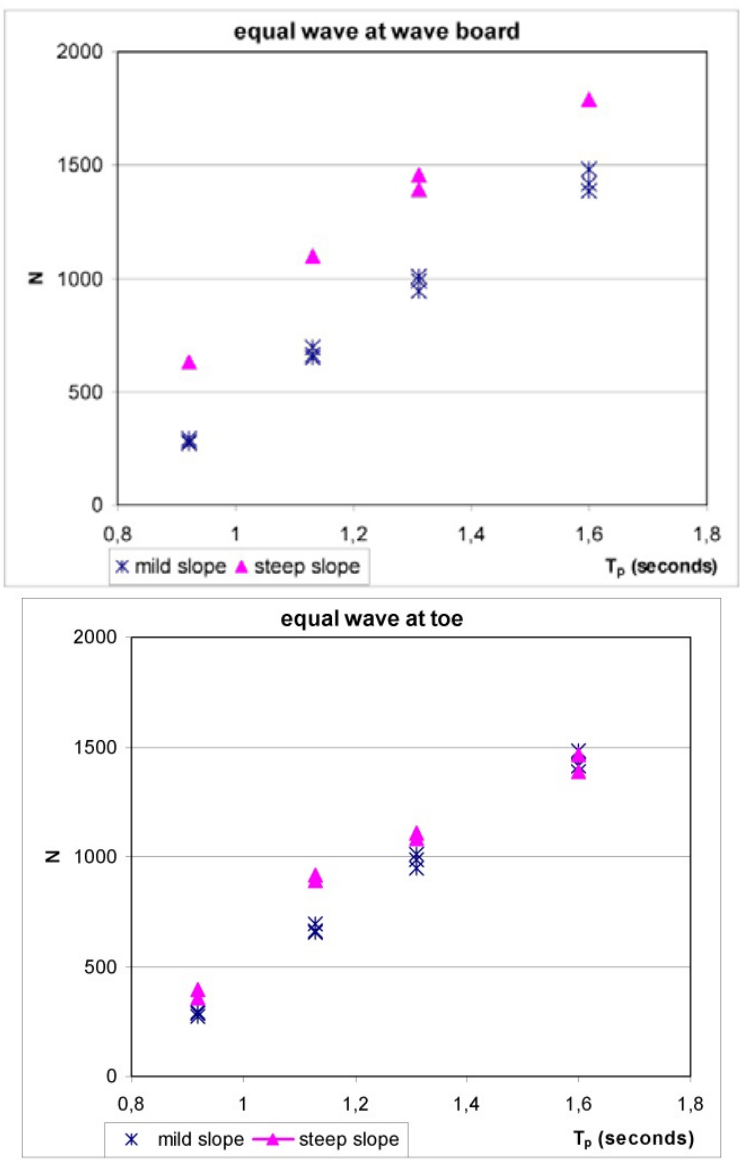

Figure 3: Results of damage tests, with identical shallow water spectra at the toe of the breakwater.

Because decomposition of the wave at the toe into a incoming wave and a reflective wave (especially for irregular waves) is rather complicated very near to a structure, a number of tests have been carried out focussing on the relation between waves at the toe for decomposed and undecomposed wave spectra. It was found that the above conclusion remains completely valid for both the decomposed as well as the undecomposed wave.

In case a physical relation is looked for which should relate the local hydraulic parameters to the stability of individual rocks, the undecomposed wave should be used. The rock is influenced by a certain hydraulic load, and it does not matter if load is caused by reflected or not-reflected waves. However, 
in case one is looking for a relation between the stability of rock slope in general as a function of an overall descriptor of the wave load, like a spectrum, one should use the decomposed waves.

\section{Tests on acceleration in currents}

Because earlier tests by a number of M.Sc. students at Delft University of Technology on propeller jets on slopes indicated that the acceleration might be relevant for the stability of stones, two lines of experiments were set up. In the first line focus was on permanent flow. In a flume a tapering was introduced. Because of this tapering the flow was accelerated. By keeping the decrease in width constant, and by varying the length of the tapering, the velocity in the tapering was equal for each test, but resulted in a different acceleration. For each combination of velocity and acceleration the critical condition for moving stones was determined. The tests showed that for a given stone size the critical velocity decreased with an increase of the acceleration. To describe this a stability parameter has been developed on the basis of the Shields parameter, but including the acceleration in the same style as is used in the Morison equation:

$$
\Psi_{M S}=\frac{\frac{1}{2} C_{B} \rho d^{2} u^{2}+C_{M} \rho d^{3} a}{\rho \Delta g d^{3}}=\frac{\frac{1}{2} C_{B} u^{2}+C_{M} d a}{\Delta g d}
$$

The entrainments function can be described as:

$$
\Phi_{E}=E d^{2} \sqrt{\frac{d}{\Delta g}}
$$

in which $E$ is $n / A T$, in which $n$ is the number of stones displaced, $A$ the area of the displaced stones and $T$ the duration of the experiment.

Regression analysis shows that the relation between the critical load and the entrainment is given by:

$$
\Phi_{E}=6 \cdot 10^{-6} \Psi_{M S}^{4.73} \quad 0.2 \leq \Psi_{M S} \leq 1.4
$$

The values of $C_{B}$ and $C_{M}$ were found as 0.10 and 3.92 [DESSENS, 2004]. The quotient $C_{M} / C_{B}=39$.

A very general form of a stability formula is the stability formula of IZBASH [1932]

$$
d_{c r i t}=I z \frac{u^{2}}{\Delta g}
$$

in which $u$ is a velocity near the stone, and $I z$ is a stability number. 


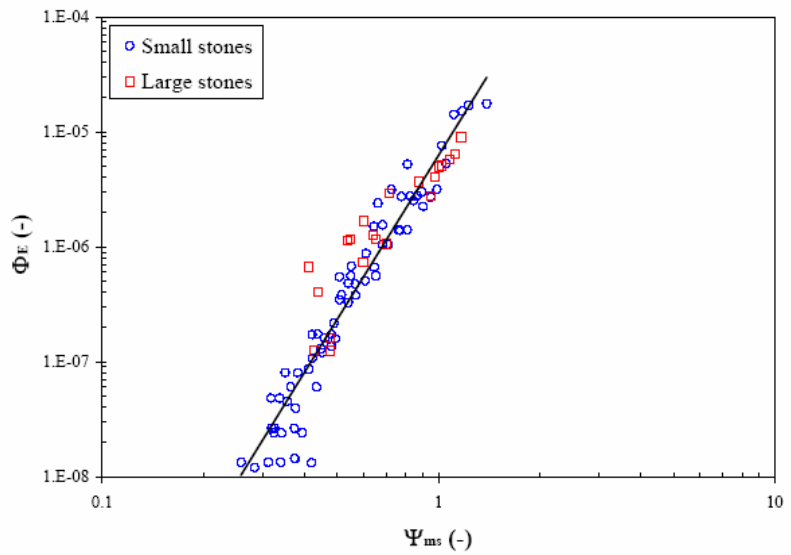

Figure 4: The dimensionless entrainment and Morison-Shields parameters for two types of stones [DESSENS, 2004]

For permanent flow this equation can be rewritten as the Shield equation, introducing both an depth-averaged velocity as well as a logarithmic velocity profile. Equation (3) and (6) can be combined to

$$
d_{\text {crit }}=A^{\prime} \frac{\frac{1}{2} C_{B} u^{2}+C_{M} d a}{\Delta g}=A \frac{u^{2}+\frac{C_{M}}{C_{B}} d a}{\Delta g}
$$

\section{Tests on acceleration in waves}

A similar test set up was made for the critical condition for movement of stones under waves. TROMP [2004] and TERRILE [2004] did tests on a 1:30 slope with regular waves. The flume was equipped with reflection compensation.

As was expected, at deep water the phase shift between velocity and acceleration is in the order of $\pi / 2$. But in a shoaling wave, the moment of maximum velocity and maximum acceleration also move to each other. This decrease in phase shift is indicated in figure 5. Because of shoaling both the acceleration and the velocity increase. However, the acceleration increases more because of the increase asymmetry of the wave.

Applying equation (3) to wave situations leads for deeper water and for horizontal beds not to an lower critical velocity. Because of the phase shift between velocity and acceleration at the moment of maximum $u$ the acceleration is zero, and consequently the component $\left(C_{M} / C_{B}\right) / a$ is also zero. 


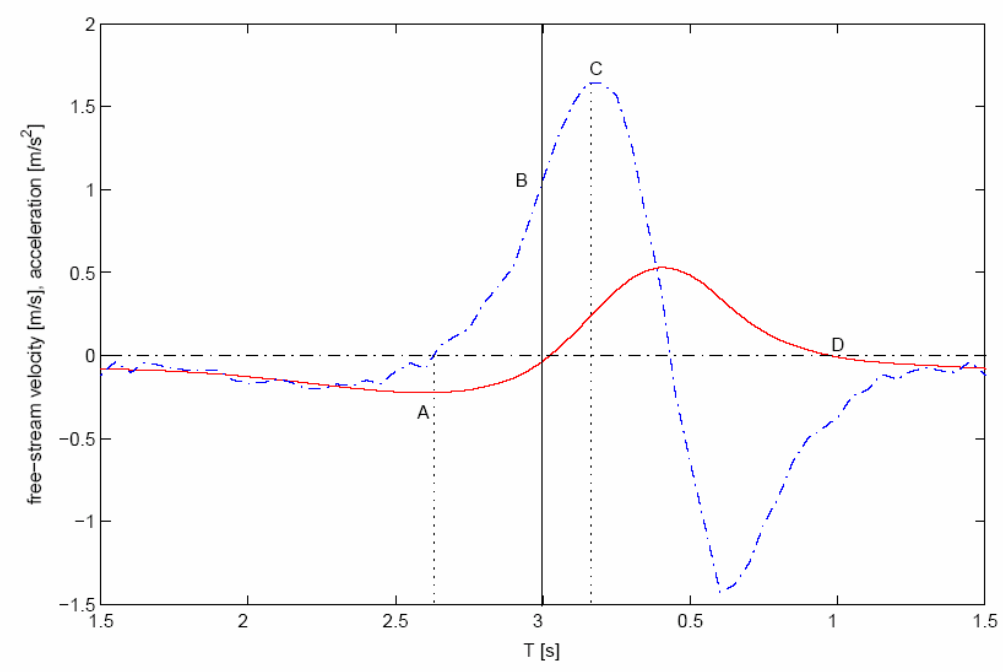

Figure 5: Instantaneous values of near-bed horizontal velocities and accelerations for a wave with $\mathrm{H}_{0}=12.5 \mathrm{~cm}, \mathrm{~h}_{0}=55 \mathrm{~cm}, \mathrm{~T}=2.5 \mathrm{~s}$ and $\mathrm{X}=18.68 \mathrm{~m}$. The solid line represents the orbital velocity and the dash-dotted line the orbital acceleration. [TERRILE, 2004]

During the tests Tromp made detailed video observations of movement of stones. The movements could be correlated to the observed near bed velocities and near bed accelerations. Figure 6 shows the movement of a stone as a function of the near bed velocities for two different waves, both with a wave height of $15 \mathrm{~cm}$, but with two different periods.
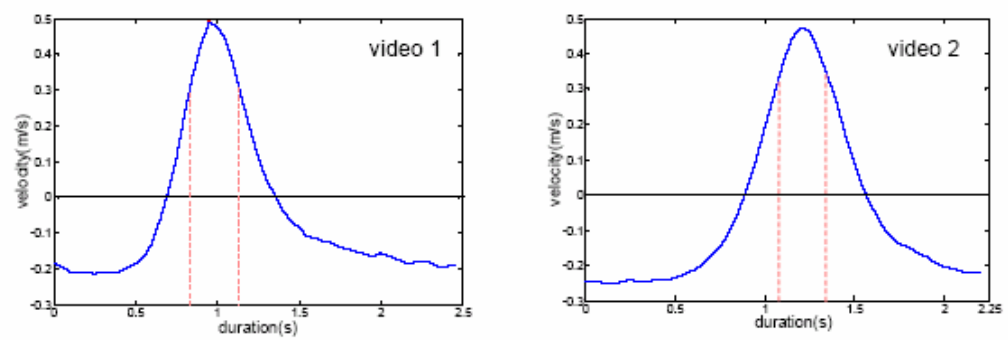

Figure 6: Velocity profile and duration of stone movement for a similar wave of 2.5 (video1) and 2.25 (video2) seconds [TROMP, 2004]

In figure 7 for the same situation the movement of the stone is plotted as a function of the acceleration. In the table below the results of this observation are summarised. It is clear that the start of motion of a stone is a function of both 
velocity and acceleration. This indicates that also for oscillatory motion a Morison-type of approach seems to be very logical.
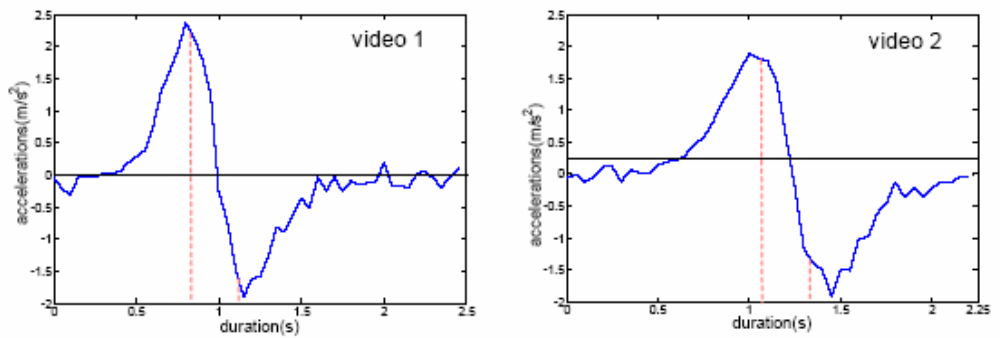

Figure 7: Acceleration profile and duration of stone movement for a similar wave of 2.5 (video1) and 2.25 (video2) seconds [TROMP, 2004]

\begin{tabular}{|l|l|l|}
\cline { 2 - 3 } \multicolumn{1}{c|}{} & critical velocity & critical acceleration \\
\hline $\mathrm{H}=15 \mathrm{~cm}, \mathrm{~T}=2.50 \mathrm{~s}$ & $0.32 \mathrm{~m} / \mathrm{s}$ & $2.2 \mathrm{~m} / \mathrm{s}^{2}$ \\
\hline $\mathrm{H}=15 \mathrm{~cm}, \mathrm{~T}=2.25 \mathrm{~s}$ & $0.39 \mathrm{~m} / \mathrm{s}$ & $1.8 \mathrm{~m} / \mathrm{s}^{2}$ \\
\hline
\end{tabular}

This can be worked out, and when a large number of tests is available, with some regression analysis the coefficients of the Morrison equation can be determined.

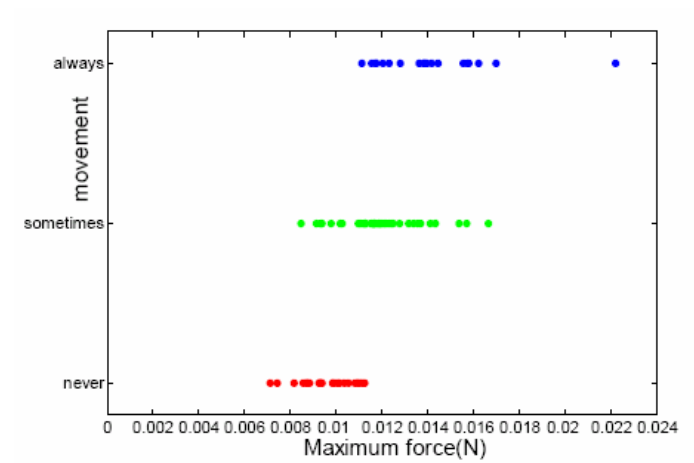

Figure 8: Movement/ no-movement of stones in one of the tests with stones of $9.6 \mathrm{~mm}$, and calibrated Morison coefficients [TROMP, 2004]

lower than in case of permanent flow.
As an example is given the test results for stones of $9.6 \mathrm{~mm}$ In figure 8 the force on a single rock is computed, using the Morisonequation (3) and the coefficients $C_{B}=0.55$ and $C_{M}=3.75$. These coefficients are different from the ones found in the experiment with permanent flow, but in the same order of magnitude. The quotient $C_{M} / C_{B}=7$, which is

Apart from the approach via Morison type equation, also a stability criterion on basis of waveforms and a stability on basis of entrainment were 
elaborated. It is outside the scope of this paper to discuss this. For details is referred to TERRILE ET AL. [2005].

\section{Relation to breakwater stability}

From the above tests follows that the stability of rock is a function of both velocity and acceleration. In deep water and in case of horizontal beds there is a phase shift of $\pi / 2$ between maximum velocity and maximum acceleration, which makes that the effect of acceleration can be neglected. However, in case of shoaling waves, especially on steep slopes, this phase difference is decreasing. At the same time the value of the acceleration is increasing relatively to the increase in the maximum velocity. Both effects make that acceleration is relevant for the determination of stability of rock on a sloping structure.

In the present stability equations the load parameter is a function of the energy density spectrum at the toe of the structure. But an energy density spectrum does not contain any information on the phase shift. Also the energy density spectrum does not contain any information on wave asymmetry. Therefore the present stability equations cannot distinguish between waves which have at the toe of the structure an identical energy density spectrum, but a different phase angle between velocity and acceleration. This phase angle depends, amongst others, on the slope of the foreshore.

Because of higher order effects the wave crests become steeper and the wave troughs become flatter. This increases the velocities and accelerations considerably. The wave steepness (as defined by the ratio between wave height and wave length) does not change, but when the steepness of only the part above the still water line is considered, this steepness increases significantly. The peakedness (kurtosis) of the waves is basically included in the wave spectrum, because it leads to a shift of energy to a higher frequency. In case the waves change from a pure sinus to a more trochoidal wave, the total energy in the spectrum remains the same, but some energy is shifted to lower frequencies. It is questionable if only using the $T_{m-1,0}$ is sufficient to account for this effect.

From the tests by Tromp and Terrile follows that, for a given velocity, the stability decreases because of the effects of acceleration. In order to take these effects into account one may start with the Van der Meer equation, and add one parameter. This parameter should have a value of 1 for deep water and horizontal foreshores. In case of a sloping foreshore this parameter should increase. Given the fact that the tests of Van Gent with structures on a steeper foreshore lead to a line which is in the order of $7 \%$ higher, on can expect that in case of steep foreshores the coefficient should get a value of 1.1. 


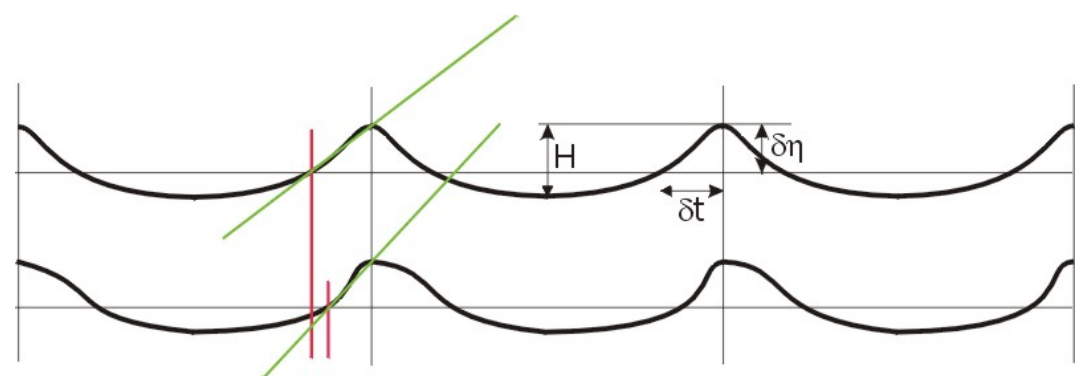

Figure 9: Definition of the relative front slope

A parameter describing the skewness of the wave is the average front slope of the wave. The front slope of the wave can be described by $\partial \eta / \partial t$. To average this value for all waves, one may use the wave height as weighing factor. This results in

$$
R=\frac{\overline{H_{i}^{2} \frac{\delta \eta_{i}^{+}}{\delta t_{i}}}}{\overline{H_{i}^{2}}}=\frac{\sum_{i}\left(H_{i}^{2} \frac{\delta \eta_{i}^{+}}{\delta t_{i}}\right)}{\sum_{i} H_{i}^{2}}
$$

This value can be made dimensionless by dividing by the wave celerity

$$
Q=\frac{R}{\bar{C}}
$$

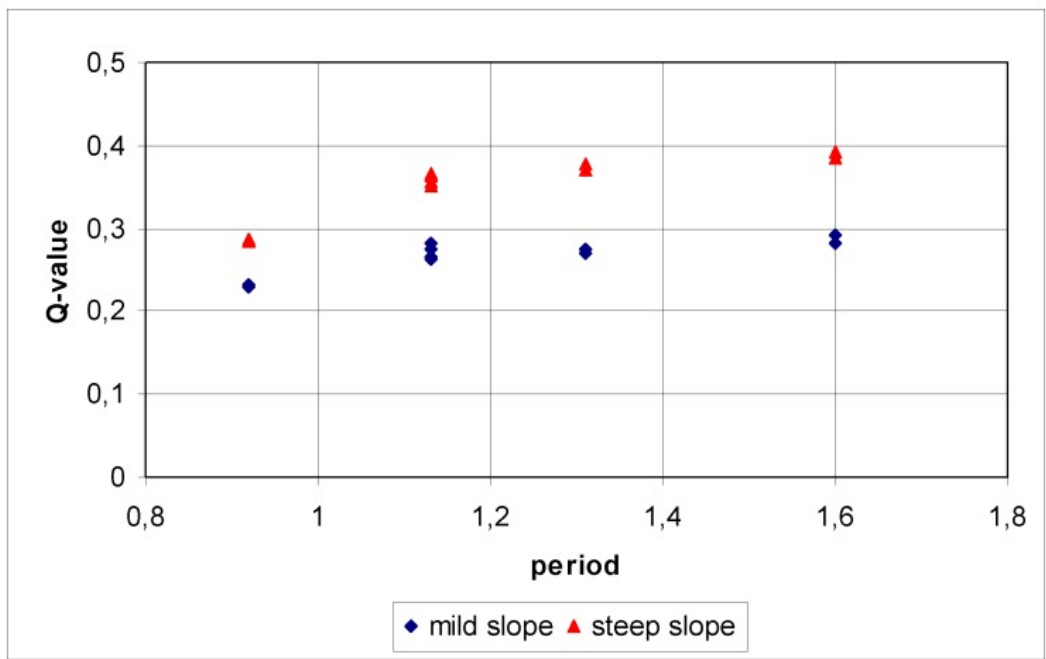

Figure 10: dimensionless wave steepness as a function of the period 
From figure 10 follows that in all cases the value of $Q$ in case of a steep slope is considerably higher. The relation between $Q_{\text {mild }}$ and $Q_{\text {steep }}$ is given in figure 10 . The relation is

$$
Q_{\text {steep }}=C_{H} Q_{\text {mild }} \text { in which } C_{H}=1.4
$$

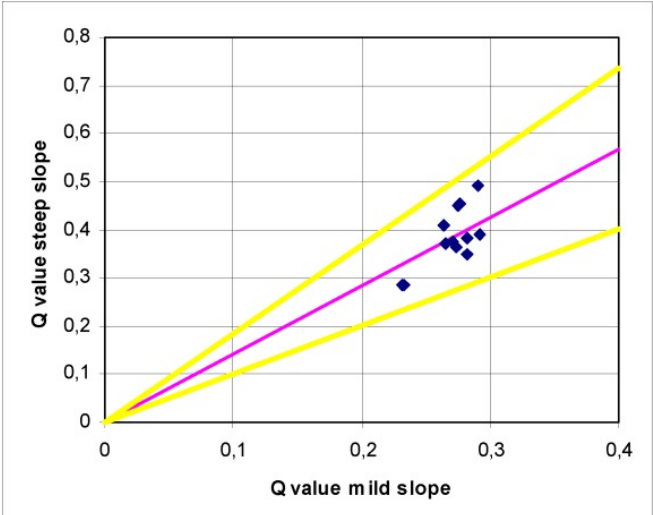

Figure 11: relation between $Q_{\text {mild }}$ and $Q_{\text {steep }}$

A analysis on the basis of the peakness parameter (acceleration descriptor) as suggested by Drake and Calatoni [2001] leads to the same conclusions. See also figure 12. However, a disadvantage of this descriptors is that that only the peakedness is included, and not the skewness.

Recently OORTMAN [2006] continued this work, and did some test on a 1:8, a 1:15 and 1:30 foreshore. He measured accelerations both in uprush and downrush. It was expected that the results for

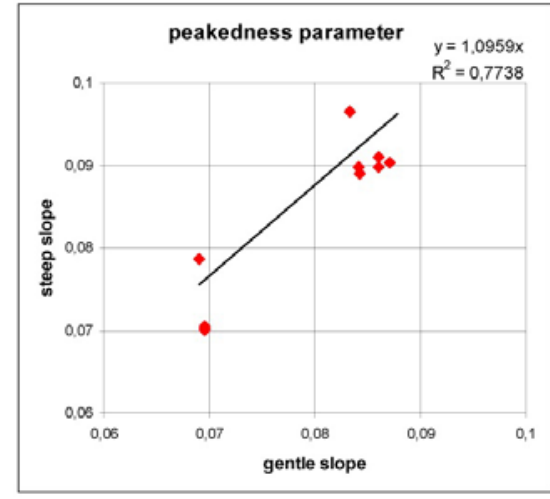

Figure 12: The peakedness parameter for various slopes

the 1:15 slope should fall in-between the 1:8 and 1:30 slope. However, as can be seen from figure 13 for the downrush the 1:15 line gives the lowest acceleration, and for the uprush this is sometimes the case. This leads to the conclusion that most probably the effect of the foreshore slope is not linear. 

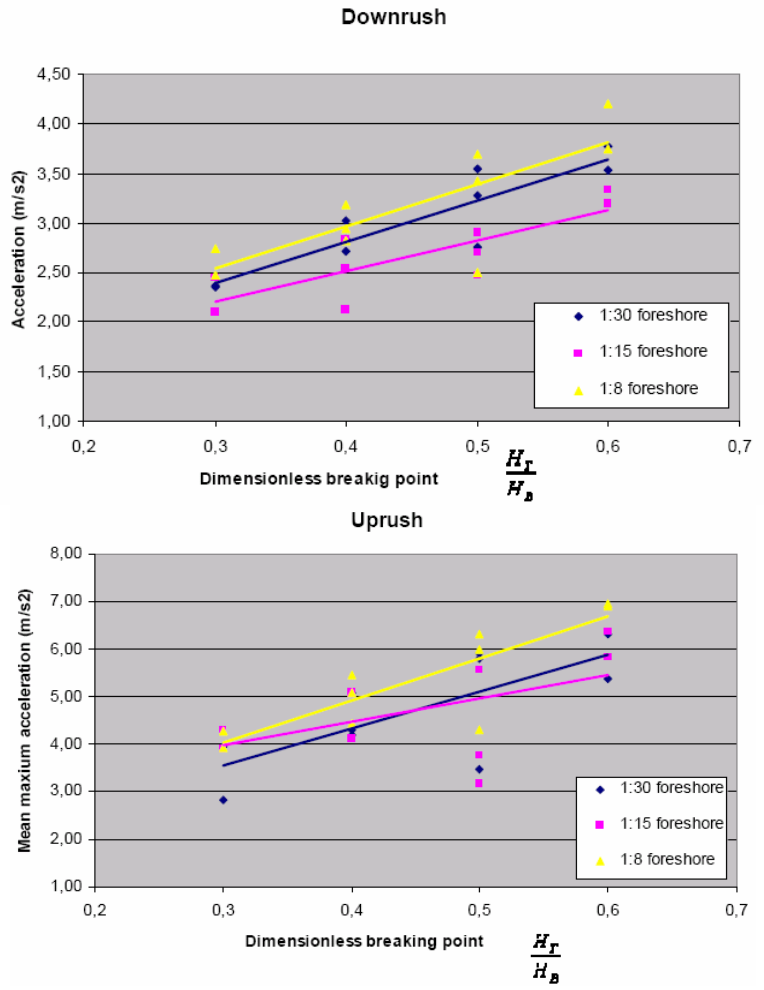

Figure 13: Acceleration during downrush and uprush as function of the dimensionless breaking point (OORTMAN, 2005)

\section{Conclusions}

It seems that the stability of rock in breakwater slopes above steep foreshores does not only depend on parameters described in a spectrum, but also on parameters like the peakedness and the wave asymmetry. A more universal stability equation should therefore include a parameter which describes these aspects. Both the front steepness of the wave as well as the peakedness of the waves are promising parameters to describe the effect. This should be investigated by analysing existing test results not only in the frequency domain, but also by analysis in the time domain.

\section{References}

Dessens, M. [2004] The influence of flow acceleration on stone stability, M.Scthesis, Delft University of Technology 
Drake, T.G., Calantoni, J. [2001]. Discrete particle mode for sheet flow sediment transport in the nearshore. J. Geophys. Res. Oceans 106 (C9), 19.85919.868 .

IzBASH, S.V. [1932] Construction of dams by dumping of stone in running water, Moscow-Leningrad (in Russian, in English available in: IzBASH, S.V. and KHALDRE, K.Yu. [1970] Hydraulics of river channel closure, Butterworth, London)

HovestaD, M [2005] Breakwaters on steep foreshores, M.Sc-thesis, Delft University of Technology,

OORTMAN, N.J. [2006] Influence of foreshore steepness on wave velocity and acceleration at the breakwater interface, M.Sc-thesis, Delft University of Technology

TERRILE, E. [2004] The threshold of motion of coarse particles by regular nonbraking waves, M.Sc-thesis Delft University of Technology and University of Genoa

Terrile, E., Stive, M.J.F, Reniers, A., Verhagen, H.J., Tromp, M. [2005] Incipient motion of course particles under regular shoaling waves, Coastal Engineering (53) pp81-92

Tromp, M. [2004] The influence that fluid accelerations have on the threshold of motion, M.Sc-thesis, Delft University of Technology

VAN DER MEER, J.W. [1988] Rock slopes and gravel beaches under wave attack, Ph.D-thesis Delft University of Technology

VAn Gent, M.R.A., Smale, A., Kuiper, C. [2003] Stability of rock slopes with shallow foreshores, proc. Coastal Structures 2003, Portland, ASCE

Note:

M.Sc. theses from Delft University are downloadable from www.hydraulicengineering.tudelft.nl, select then Education, and MSc theses. 
KEYWORDS - ICCE 2006

THE EFFECT OF FORESHORE SLOPE ON BREAKWATER STABILITY Henk Jan Verhagen, Bas Redijk and Markus Muttray

Abstract number 713 /Paper 492

Breaking waves

Breakwaters

Coastal structures

Wave asymmetry

Armour stability

Steep foreshore 